\title{
Cointegration And The Causality Between Stock Prices And Exchange Rates Of The Korean Economy
}

\author{
Jae-Kwang Hwang, (E-mail: jhwang@vsu.edu), Virginia State University
}

\begin{abstract}
This paper examines the relationship between stock prices and exchange rates in Korea. It is found that two time series are cointegrated by the Engle-Granger two-step cointegration test. The results show that domestic currency devaluation has a negative short-run effect on stock prices. It means that there is only one-way temporal linkage from exchange rates to stock prices.
\end{abstract}

\section{Introduction}

t is suggested by "Flow-oriented" models of exchange rates and "Stock-oriented" models of exchange rates that there would be causal relationship between stock prices and exchange rates. For instance, stock prices are determined by the present values of their future cash flows so expectations of relative
currency values play a considerable role in their price movements especially for internationally held financial assets. Therefore, stock price innovations may affect or be affected by exchange rate dynamics.

Exchange rates may share many of the general behavioral characteristics of the prices of assets that are traded on organized exchanges, such as common stocks, long-term bonds, and agricultural commodities. Monthly changes in the prices of these assets are largely random and unpredictable. The prices of assets traded in organized markets suggest that there could be some common elements in the behavior of such prices. When we observe the day-to-day fluctuations of exchange rates in response to news, we see that the behavior of the stock market prices in response to news looks very similar to that of exchange rates. In particular, this paper tries to find out the interaction between stock prices and exchange rates. In other words, changes in stock prices cause changes in exchange rates or vice versa.

There have been lots of empirical studies [Smith (1992), Soenen and Hennigar (1988), Solnik (1987)] on the relationship between two financial variables. Bahmani-Oskooee and Sohrabian (1992), using S\&P 500 Stock Index and the effective exchange rate of the dollar over the period July 1973 to December 1988, show there is bidirectional causality between stock prices and exchange rates in short-run but not in long-run.

On the other hand, Abdalla and Murinde (1997) show unidirectional causality from exchange rates to stock prices in three countries out of four developing countries. They found that exchange rates Granger-cause stock prices in Korea, Pakistan, and India, while stock prices Granger-cause exchange rates in the Philippines.

Ajayi and Mougoue (1996) examined the intertemporal relation between stock prices and exchange rates for the developed countries by using daily data from April 1985 to July 1991. They found that an increase in aggregate stock price has a negative short-run effect on domestic currency value because of inflation expectations, but increases in domestic stock prices induces domestic currency appreciation in long-run. However, currency depreciation has a negative short-run and long-run effect on the stock market. Most recently, Islam (2003) and Maysami and Hui (2001) examined the causality between stock returns and financial variables.

The purpose of this paper is to figure out the relationship between two financial variables in Korea. The two time series are cointegrated by the Engle-Granger (1987) methodology. It means that we can build an error- 
correction model to examine the short-run dynamics between two time series. The next chapter discusses the methodology, applies it to the data and presents the empirical results. Chapter III concludes this paper.

\section{Methodology And Evidence}

\subsection{Data}

The data consists of monthly stock market indices and exchange rates for the period of 1980:1 to 1997:7. Monthly data on the stock market index $(1980=100)$ are obtained from Korean Stock Exchange Market and monthly bilateral exchange rates of the won-dollar are obtained from International Financial Statistics. Both variables are the values of the end of each month and are expressed in logarithmic form. The reason for this sample period is to avoid the structural break in exchange rate from the financial crisis in Korea. After the financial turmoil, the value of the Korean won has been depreciated so much.

\subsection{Preliminary Test: Unit Roots}

We first need to test for stationarity and the order of integration of the variables. In other words, we examine whether stock prices and exchange rates contain unit root. If a series is integrated of order $d$, denoted I $(d), d$ is the number of times the series must be differenced to achieve stationary.

We implement the augmented Dickey-Fuller (1979) (ADF) test and the Kwiatkowski, Phillips, Schmidt, Shin (1992) (KPSS) test. The Dickey-Fuller-type unit root tests are criticized because their failure to reject the null hypothesis may be attributed to their low power against weakly stationary alternatives. However, KPSS tests the null hypothesis of stationary against the alternative of a unit root. To implement the augmented Dickey-Fuller test, we estimate the regression,

$\Delta X_{t}=\alpha+\beta X_{t-1}+\sum_{j=1}^{k} \gamma_{j} \Delta X_{t-j}+\varepsilon_{t}$

where $\Delta$ is the difference operator, $\mathrm{X}$ is the series being tested, $k$ is the number of lagged differences and is selected such that the Ljung-Box Q-statistics fails to reject the null of no serial correlation in the residual of equation (1). If the t-statistics is less than the critical values, then the null hypothesis of a unit root $(\beta=0)$ cannot be rejected. However, if the t-ratio is larger than the critical value, the null hypothesis of nonstationarity can be rejected.

KPSS test statistics is

$\eta_{\mathrm{u}}=\mathrm{T}^{-2} \sum\left(S_{t}^{2} / S^{2}(L)\right)$

where

$$
\begin{aligned}
& \mathrm{S}_{\mathrm{t}}=\sum_{i=1}^{t} \mathrm{e}_{\mathrm{t}} \\
& \mathrm{S}^{2}=\boldsymbol{T}^{-1} \sum_{t=1}^{T} e_{t}^{2}+2 T^{-1} \sum_{s=1}^{L}\left(1-\frac{s}{(L+1)}\right) \sum_{t=s+1}^{T} e_{t} e_{t-s}
\end{aligned}
$$

$\mathrm{S}_{\mathrm{t}}$ is the partial sum process of the residual $e, \mathrm{~T}$ is the number of observations, and $\mathrm{L}$ is the lag length. If the test statistic is greater than the critical values, the null hypothesis of stationarity is rejected in favor of the unit root alternative. 
The results of the ADF test are reported in Table 1. The results show that exchange rates and stock prices are not stationary in levels but the null hypothesis of non-stationarity is rejected at the $1 \%$ levels of significance after two variables have been first differenced. Therefore, two variables are $I(1)$.

The results of the KPSS tests are also reported in Table 1 . The null of stationarity of the levels is rejected at the $1 \%$ significance for both stock prices and exchange rates. However, when the first differences of the variables are tested, the null hypothesis of stationarity is not rejected. As a result of two tests, the exchange rates and stock prices are nonstationary in levels but stationary in first differenced form.

\subsection{Cointegration Test}

With the previous results of unit root tests, we have two $I(1)$ variables. We can test whether there is a longrun relationship between exchange rates and stock prices. Cointegration test can be used to examine stable long-run relations between two or more variables. Cointegration means that one or more combination of the variables is stationary even though each variable is not. If there exists cointegration between variables, we can test short-run dynamics between two series within the framework of an error correction model.

This paper implements the regression-based Engle-Granger (1987) methodology. Following Engle and Granger (1987), the cointegration test is based on the following equations:

$\mathrm{EX}_{\mathrm{t}}=\alpha+\beta \mathrm{SP}_{\mathrm{t}}+\varepsilon_{\mathrm{t}}$

$\Delta \varepsilon_{\mathrm{t}}=\beta \varepsilon_{\mathrm{t}-1}+\sum_{\mathrm{j}=1}^{k} \Delta \varepsilon_{\mathrm{t}-\mathrm{j}}$

where EX is exchange rate of the won-dollar, SP is Korean stock index, and $\varepsilon$ is an error term. If the error term $(\varepsilon)$ is stationary, two variables are cointegrated. We apply the ADF test to check the stationarity of the residual series $(\varepsilon)$. The reported t-test statistic for $\beta$ is -2.21 . The critical values are $-2.576,-1.941$, and -1.617 at the 1 percent, 5 percent, and 10 percent level, respectively. Therefore, the null hypothesis of no cointegration is rejected at the 5 percent level.

\subsection{Error Correction Model}

If the series are cointegrated, their time paths are influenced by the extent of any deviation from long-run equilibrium. Therefore, the short-run dynamics are influenced by the deviation from the long-run equilibrium. According to the Granger representation theorem, for any set of $I(1)$ variables, error correction and cointegration are the same representation. Since exchange rates and stock prices are cointegrated, an error correction model can be constructed. To build an error-correction model, regress the first difference of each variable in the cointegration equation on lagged values of the first differences of all of the variables and lagged values of the error term from the cointegration equation.

The following error correction form can represent two cointegrated variables:

$$
\begin{gathered}
\Delta E X_{t}=\alpha_{1} V_{t-1}+\sum_{i=1}^{m_{1}} \lambda_{i} \Delta E X_{t-i}+\sum_{j=1}^{m_{2}} \phi_{j} \Delta S P_{t-j}+\varepsilon t \\
\Delta S P_{t}=\alpha_{2} V_{t-1}+\sum_{i=1}^{m_{3}} \delta_{i} \Delta E X_{t-i}+\sum_{j=1}^{m_{4}} \xi_{j} \Delta S P_{t-j}+\mu_{t}
\end{gathered}
$$

where $\mathrm{V}_{\mathrm{t}-1}$ is the error correction term. These error correction coefficients, $\alpha_{1}$ and $\alpha_{2}$, capture long-run dynamics between stock prices and exchange rates, whereas the coefficients on $\Delta \mathrm{SP}_{\mathrm{t}-\mathrm{j}}$ and $\Delta \mathrm{EX}_{\mathrm{t}-\mathrm{i}}$ are expected to estimate short-run dynamics between two variables. 
It is very important to choose the appropriate lag length $(k)$ in an error correction model. To determine the lag structure of an error correction model, this paper uses the general-to-specific method. Equations (5) and (6) are initially estimated with $k$ arbitrarily set equal to 13 . This unrestricted model is tested against a restricted model with $k$ reduced to 12 . The reported likelihood ratio statistic shows that we cannot reject the restriction. This process will be continued until the restriction is rejected. As a result, the appropriate lag length is specified with $k=3$.

Table 2 presents the estimation results for both exchange rates and stock prices. The parameters $\alpha_{1}$ and $\alpha_{2}$ are expected to capture the adjustments of $\Delta \mathrm{SP}_{\mathrm{t}}$ and $\Delta \mathrm{EX}$ towards long-run equilibrium. Since $\alpha_{1}$ and $\alpha_{2}$ are statistically significant, it suggests that there is a long-run causality between two variables. To examine short-run effects between two markets, see the coefficients on $\Delta \mathrm{SP}_{\mathrm{t}-\mathrm{j}}$ and $\Delta \mathrm{EX}_{\mathrm{t}-\mathrm{i}}$. The negative $\phi_{\mathrm{j}}$ coefficients on $\Delta \mathrm{SP}_{\mathrm{t}-\mathrm{j}}$ imply that an immediate past increase in stock price has a negative effect on the exchange rate (i.e., appreciation of domestic currency), but statistically insignificant. The negative $\delta_{\mathrm{i}}$ coefficients on $\Delta \mathrm{EX}_{\mathrm{t}-\mathrm{i}}$ suggest that an immediate past increase in the exchange rate (devaluation of domestic currency) has a negative influence on the stock price, but not individually significant.

As the results of the joint hypotheses $\mathrm{H}_{0}$ : $\phi_{\mathrm{j}}=0$ and $\mathrm{H}_{0}: \delta_{\mathrm{i}}=0$ using F- test, we can not reject the null hypotheses of $\phi_{\mathrm{j}}=0$ but can reject the null hypotheses of $\delta_{\mathrm{i}}=0$. Therefore, exchange rates only do Granger-cause stock prices in short-run.

We carried out some diagnostic tests such as heteroscedasticity, auto-correlation and structural break for the error correction model. The results of these tests are reported at Table 2. As these results show, the error correction model specifications are homoscedastic, serially independent and no structural break. As Figure 1 shows, the plot of CUSUM test suggests the parameter stability.

An alternative way to decide the lag length in this paper is to use Akaike's Final Prediction Error criteria. The lag structure that minimizes the FPE is chosen. Table 3 shows the error-correction estimation based on the Akaike's Final Prediction Error criterion. Since the parameters $\alpha_{1}$ and $\alpha_{2}$ are significant, there is a long-run relationship between two variables. Likewise, there is an evidence of unidirectional causality from exchange rates to stock prices.

Based on these results, movements in exchange rate have great implications for stock prices in long-run as well as in short-run. In long-run, currency depreciation may have a positive influence on stock prices. The reason is that Korea is an export-dominant economy so currency depreciation can increase the exports of firms, and in turn affect the share price of the firm. In short-run, currency depreciation may have a negative effect on stock markets because of the expectation of high inflation, which may give a negative influence on the stock market.

\section{Summary And Conclusion}

In this paper an attempt has been made to examine the relation between stock prices and exchange rates in Korea. We perform the ADF test and the KPSS test to check the stationarity of two variables. Then we move to test for cointegration between two variables using the regression-based Engle-Granger procedure. Based on the residuals from the Engle-Granger regression, two variables are cointegrated. Next, an error correction model is constructed to examine the interaction between stock prices and exchange rates.

Among the findings of interest, two series are cointegrated in this paper whereas Abdalla and Murinde (1997) find no cointegration between two variables for the case of Korea. This paper shows that domestic currency devaluation has a negative effect on stock prices in short-run. It means that changes in exchange rates do affect the exports of firms and ultimately affect stock prices. Therefore, there would be bi-directional interaction between stock prices and exchange rates in long-run but one-way interaction from exchange rates to stock prices in short-run in Korea. 


\section{References}

1. Abdalla, Issam.; Murinde, Victor. "Exchange rate and stock price interactions in emerging financial markets: evidence on India, Korea, Pakistan and the Philippines", Applied Financial Economics, 7, 1997, pp. 25-35.

2. Ajayi, Richard A.; Mougoue, Mbodja. "On the dynamic relation between stock prices and exchange rates", The Journal of Financial Research, 19, 1996, pp. 193-207.

3. Bahmani-Oskooee, M; Sohrabian, A. "Stock prices and the effective exchange rate of the dollar", Applied Economics, 24, 1992, pp. 459-64.

4. Dickey, David; Fuller, Wayne. "Distribution of the estimator for autoregressive time series with a unit root", Journal of American Statistical Association, 74, 1979, pp. 427-31.

5. Engle, R. F.; Granger, C. W. "Co-integration: representation, estimation, and testing”, Econometrica, 55, 1987, pp. 251-76.

6. Islam, M. "Cointegration and the Causality between the Real Sector and the Financial Sector of the Malaysian Economy", Journal of American Academy of Business, 2, 2003, pp. 560-568.

7. Kwiatkowski, Denis; Phillips, Peter; Schmidt, Peter; Shin, Yongcheol. "Testing the null hypothesis of stationary against the alternative of a unit root: How sure are we that economic time series have a unit root", Journal of Econometrics, 54, 1992, pp. 159-78.

8. Maysami, R.C.; Hui, S. "Economic Forces and Stock Returns: A General-To-Specific ECM Analysis of the Japanese and South Korean Markets", International Quarterly Journal of Finance, 1, 2001, pp. 83-101.

9. Smith, C. "Stock markets and the exchange rate: a multi-country approach", Journal of Macroeconomics, 14, 1992, pp. 607-29.

10. Soenen, L.; Henningar, E. "An analysis of exchange rates and stock prices-the US experience between 1980 and 1986", Akron Business and Economic Review, 19, 1988, pp. 7-16.

11. Solnik, B. "Using financial prices to test exchange rate models: a note", Journal of Finance, 42, 1987, pp. 141-9.

\section{FIGURE 1: CUSUM Test}

The CUSUM test is based on the statistic

$$
W_{t}=\frac{1}{s} \sum_{\tau=k+1}^{t} \omega_{\tau} \quad \mathrm{t}=\mathrm{k}+1, \ldots \mathrm{T}
$$

where $\mathrm{s}$ is the standard error of the regression fitted to all $\mathrm{T}$ sample points. $\omega_{\tau}$ is the recursive residuals.

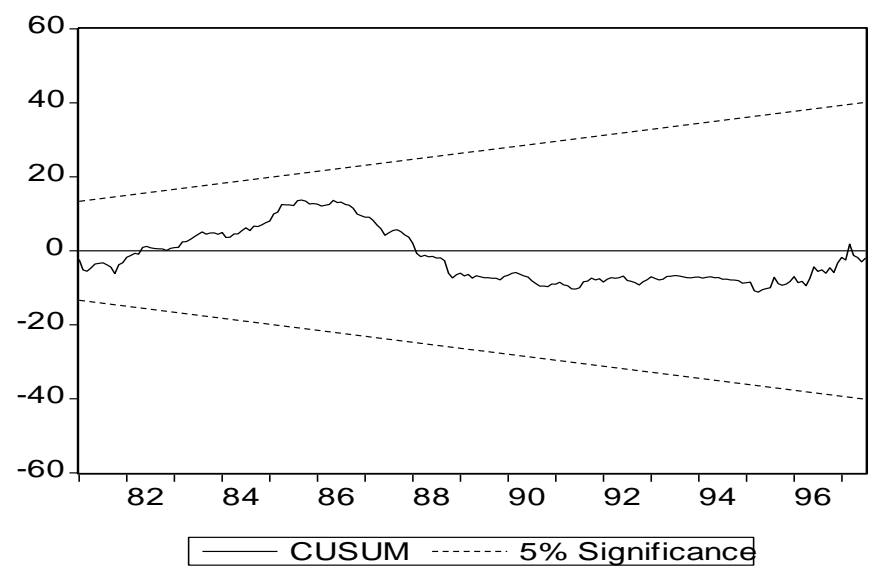


Table 1: Unit Root Test

\begin{tabular}{|c|c|c|c|c|}
\hline \multirow{2}{*}{ Variables } & \multicolumn{2}{|c|}{ ADF test $^{\text {a }}$} & \multicolumn{2}{c|}{ KPSS test $^{{ }^{\mathrm{b}}}$} \\
\cline { 2 - 5 } & Levels & First-differences & Levels & First-differences $^{*}$ \\
\hline EX & $-1.782(9)$ & $-4.478(2)^{* * *}$ & $0.740^{* * *}$ & $0.458^{*}$ \\
\hline SP & -1.265 & $-14.735 * * *$ & $3.747 * * *$ & 0.295 \\
\hline
\end{tabular}

Notes: ***, * denote significance at the 1 percent and 10 percent level, respectively. EX is the exchange rate between won and the U.S. dollar and $\mathrm{SP}$ is the stock price in Korea. These variables are expressed in logarithm.

a ADF test: Numbers in the table are the pseudo t-statistics for testing the null hypothesis that the series is nonstationary. The critical values of the ADF test statistic with a constant are $-3.464,-2.876$, and -2.574 at the 1 percent, the 5 percent, and 10 percent, respectively. Lag length $k$ in parentheses is selected such that the Ljung-Box Q-statictic fails to reject the null hypothesis of no serial correlation of the residuals.

b KPSS test: The null hypothesis is that the series is stationary. The reported test statistics are computed using lag length that equals 4 . The 1 percent, 5 percent, and 10 percent critical values are $0.739,0.463$, and 0.347 , respectively.

Table 2: Estimation Of Error-Correction Model

\begin{tabular}{|c|c|c|}
\hline Dependent Variable & $\Delta \mathbf{E X}$ & $\Delta \mathbf{S P}$ \\
\hline Constant & $0.0007(1.30)$ & $0.0152(3.10)^{* * *}$ \\
\hline EC-term & $-0.0125(-2.22)^{* *}$ & $0.1162(2.37)^{* *}$ \\
\hline$\Delta$ EXt-1 & $0.3266(4.65)^{* * *}$ & $-0.8269(-1.34)$ \\
\hline$\Delta$ EXt-2 & $0.1709(2.34)^{* *}$ & $-0.4300(-0.67)$ \\
\hline$\Delta$ EXt-3 & $0.1618(2.31)^{* *}$ & $-1.0772(-1.75)^{*}$ \\
\hline$\Delta$ SPt-1 & $-0.0059(-0.74)$ & $-0.0861(-1.23)$ \\
\hline$\Delta$ SPt-2 & $0.0042(0.52)$ & $0.0127(0.18)$ \\
\hline$\Delta$ SPt-3 & $-0.0030(-0.38)$ & $-0.1362(-1.94)^{*}$ \\
\hline
\end{tabular}

Notes: *,**, and *** denote significance at the 10 percent, 5 percent, and 1 percent level, respectively. $\mathrm{t}$-statistics are in parentheses.

- Test results for heteroscedasticity, autocorrelation and structural break for the error correction model

\begin{tabular}{|c|c|c|}
\hline Null hypothesis & Test statistic & Conclusion \\
\hline No heteroscedsticity & $1.15(0.27)$ & ${\text { Accept } \mathrm{H}_{0}}$ \\
\hline No autocorrelation & First order $=1.28(0.26)$ & Accept $\mathrm{H}_{0}$ \\
& Second order $=1.12(0.33)$ & Accept $\mathrm{H}_{0}$ \\
& Third order $=1.74(0.16)$ & ${\text { Accept } \mathrm{H}_{0}}$ \\
\hline No structural break & $1.02(0.42)$ & ${\text { Accept } \mathrm{H}_{0}}$ \\
\hline
\end{tabular}

The values in parentheses are the marginal significance levels.

Table 3: Estimation Of Error-Correction Model With The FPE Criterion

\begin{tabular}{|c|c|c|}
\hline Dependent Variable & $\Delta \mathbf{E X}$ & $\Delta$ SP \\
\hline Constant & $0.0007(1.26)$ & $0.0120(2.58)^{* * *}$ \\
\hline EC-term & $-0.0126(-2.23)^{* *}$ & $0.1110(2.21)^{* *}$ \\
\hline$\Delta \mathrm{EXt}-1$ & $0.3311(4.80)^{* * *}$ & $-1.4262(-2.69)^{* * *}$ \\
\hline$\Delta \mathrm{EXt}-2$ & $0.1700(2.36)^{* *}$ & - \\
\hline$\Delta \mathrm{EXt}-3$ & $0.1670(2.43)^{* *}$ & - \\
\hline$\Delta$ SPt-1 & - & $-0.0887(-1.25)$ \\
\hline
\end{tabular}

Notes: $* *, * * *$ denote significance at the 5 percent and 1 percent level, respectively. t-statistics are in parentheses. 